DOI: $10.1590 / 1809-6891 v 19 \mathrm{e}-47159$ MEDICINA VETERINÁRIA

\title{
SUSCEPTIBILIDADE DE Staphylococcus aureus ISOLADOS DE LEITE CRU A ANTIBIÓTICOS COMERCIAIS
}

\section{SUSCEPTIBILITY OF Staphylococcus aureus ISOLATED FROM RAW MILK TO COMMERCIAL ANTIBIOTICS}

\author{
Aparecida Selsiane Sousa Carvalho ${ }^{1}$ \\ Josilene Lima Serra² \\ Lucélia da Cunha Rodrigues ${ }^{2}$ \\ Luciano de Souza Rodrigues Junior ${ }^{2}$ \\ Adenilde Nascimento Mouchrek ${ }^{3}$ \\ Elka Machado Ferreira ${ }^{4^{*}}$
}

\author{
${ }^{1}$ Universidade Estadual do Norte Fluminense, Campos de Goytacazes, RJ, Brasil. \\ ${ }^{2}$ Instituto Federal do Maranhão, São Luiz, MA, Brasil. \\ ${ }^{3}$ Universidade Federal do Maranhão, Barreirinhas, MA, Brasil. \\ ${ }^{4}$ Universidade Estadual Paulista, Jaboticabal, SP, Brasil. \\ *Autora para correspondência - elka.ferreira@hotmail.com
}

\section{Resumo}

O leite possui extremo valor na dieta humana e constitui um excelente substrato para o crescimento de grande diversidade de microrganismos, dentre eles o Staphylococcus aureus, frequentemente encontrado no leite cru, e que se destaca como um dos microrganismos mais prevalentes em casos de mastite bovina no mundo. Objetivou-se avaliar a sensibilidade de cepas de $S$. aureus isoladas de leite cru à antimicrobianos comerciais. Para isso, selecionaram-se antibióticos com base em pesquisas junto a estabelecimentos comerciais de medicamentos veterinários no município de Zé Doca, Estado do Maranhão, Brasil. Esses antibióticos foram identificados por associação à base de penicilina, estreptomicina, isoniazida e prednisolona (BPC), oxitetraciclina base (TOR), associação à base de penicilina e estreptomicina (MPP) e cloridrato de tetraciclina (TCA). Posteriormente, realizou-se contagem de Staphylococcus spp., com isolamento e identificação bioquímica das cepas de S. aureus, as quais, em seguida, foram submetidas à antibiogramas com identificação de cepas produtoras de beta-lactamase. Os resultados demonstraram contaminação em todas as amostras por Staphylococcus spp., com contagens de $1,9 \times 10^{3}$ a 5,24 × $10^{6} \mathrm{UFC} / \mathrm{mL}$. Dentre os antibióticos testados, o TOR apresentou maior eficiência na eliminação ou redução de todas as cepas de $S$. aureus. Verificou-se que 50\% das cepas de S. aureus isoladas produziram enzima beta-lactamase. Torna-se necessário a criação de medidas de combate ao surgimento de novas cepas bacterianas e atuação das autoridades públicas, fiscalizando a comercialização de medicamentos veterinários.

Palavras-chave: beta-lactamase; produtos lácteos; qualidade do leite; resistência bacteriana.

\begin{abstract}
Milk is extremelly valuable to the human diet and an excellent substrate for the growth of a wide range of microorganisms, including Staphylococcus aureus, frequently found in raw milk and one of the most prevalent microorganisms in cases of bovine mastitis in the world. The objective of this study was to evaluate the sensitivity of $S$. aureus strains isolated from raw milk to commercial
\end{abstract}


antimicrobials. For this end, antibiotics based on research were selected from commercial establishments of veterinary drugs in the municipality of Zé Doca (Maranhão State, Brazil). The antibiotics were identified by association with penicillin, streptomycin, isoniazid and prednisolone (PCB), oxytetracycline base (TOR), a combination of penicillin and streptomycin (MPP), and tetracycline hydrochloride (TCA). Subsequently, Staphylococcus spp. counting was perfomed, with isolation and biochemical identification of strains of $S$. aureus, which were then submitted to antibiograms with identification of beta-lactamase producing strains. The results showed contamination in all samples by Staphylococcus spp., with counts ranging from $1.9 \times 10^{3}$ to $5.24 \mathrm{x}$ $10^{6} \mathrm{CFU} / \mathrm{mL}$. Among the antibiotics tested, TOR showed the highest efficiency in elimination or reduction of all $S$. aureus strains. We found that $50 \%$ of $S$. aureus strains isolated produced the enzyme beta-lactamase. It is necessary to create measures to combat the emergence of new bacterial strains and to promote action by public authorities, supervising the commercialization of veterinary drugs.

Keywords: bacterial resistance; beta-lactamase; dairy products; milk quality.

Recebido em: 28 de maio de 2017.

Aceito em: 19 de abril de 2018.

\section{Introdução}

O leite bovino é um fluído composto por uma série de nutrientes sintetizados na glândula mamária, dentre eles água, carboidratos (basicamente lactose), gordura, proteína (principalmente caseína e albumina), vitaminas e sais minerais ${ }^{(1)}$. Dessa forma, constitui-se em um alimento de extremo valor na dieta humana, além de excelente substrato para o crescimento de grande diversidade de microrganismos. A disponibilidade de nutrientes no leite, sua alta atividade de água e seu pH próximo da neutralidade favorecem o crescimento microbiano, principalmente no leite cru, devido à falta de tratamento térmico que elimine a microbiota acompanhante ${ }^{(2)}$.

Dentre as bactérias que podem ser encontradas no leite cru, destaca-se o Staphylococcus aureus, microrganismo prevalente em casos de mastite bovina em todo o mundo, capaz de produzir uma grande variedade de exoproteínas causadoras de doenças veiculadas por alimentos ${ }^{(3)}$. A mastite bovina reduz a qualidade e quantidade da produção de leite e pode ter seu tratamento pela utilização de antibióticos. No entanto, o uso indiscriminado desses produtos tem levado ao desenvolvimento de cepas de $S$. aureus multirresistentes aos antibióticos ${ }^{(4)}$.

O uso de pequenas concentrações de antibióticos no tratamento de doenças bovinas é capaz de ocasionar a morte ou a inibição do crescimento bacteriano. Porém, quando utilizados excessivamente, podem se tornar ineficazes em virtude da seleção de cepas resistentes ${ }^{(5)}$. A resistência a determinado antimicrobiano pode constituir uma propriedade intrínseca de uma espécie bacteriana ou uma capacidade adquirida. Para adquirir resistência, a bactéria deve alterar seu DNA por duas formas: indução de mutação no DNA nativo ou introdução de um DNA estranho, genes de resistência que podem ser transferidos entre gêneros ou espécies diferentes de bactérias ${ }^{(6)}$.

As infecções causadas por patógenos resistentes a antibióticos constituem um problema de saúde pública, uma vez que os microrganismos patogênicos podem ganhar resistência a todos os antibióticos antes eficazes, levando, assim, a um aumento incontrolado de epidemias causadas por doenças 
bacterianas que não poderão ser tratadas ${ }^{(7)}$.

No munícipio de Zé Doca, estado do Maranhão, Brasil, ainda prevalece a produção e comercialização de leite cru no mercado informal por pequenos produtores, fato preocupante porque na maioria das propriedades não existe um acompanhamento da saúde do animal por um profissional qualificado. Dessa forma, a segurança alimentar desse produto pode ser comprometida pelo uso indiscriminado de antibióticos e, consequentemente, pela presença de patógenos resistentes a antibióticos, colocando em risco a saúde do consumidor. Portanto, torna-se de extrema importância monitorar as cepas de $S$. aureus resistentes a antibióticos comerciais em leite cru produzido neste município, para que haja um controle desse microrganismo, de modo a minimizar o risco de exposição da população. Diante disso, objetivou-se avaliar a sensibilidade de antimicrobianos veterinários a cepas de $S$. aureus isoladas de leite cru.

\section{Material e Métodos}

Foram adquiridas 21 amostras de leite cru provenientes de sete fazendas leiteiras localizadas no município de Zé Doca, MA. Para cada propriedade foram realizadas três coletas sendo a unidade amostral obtida da produção diária total dos pequenos produtores. As amostras foram coletadas em frascos estéreis sob as mesmas condições de venda do produto e devidamente identificadas. Em seguida foram transportadas em caixas isotérmicas ao laboratório de Microbiologia de Alimentos do Instituto Federal de Educação, Ciência e Tecnologia do Maranhão, IFMA, Campus Zé Doca, para quantificação de Staphylococcus spp. conforme técnica preconizada pelo Compendium of Methods for the Microbiological Examination of Foods (APHA) ${ }^{(8)}$. As colônias com características de $S$. aureus foram estocadas em frascos com meio Ágar Triptona de Soja, armazenadas sob refrigeração e posteriormente encaminhadas ao laboratório de Microbiologia do Programa de Controle de Qualidade de Água e Alimentos (PCQA) da Universidade Federal do Maranhão para execução dos testes de coloração de Gram e provas bioquímicas de coagulase, catalase e utilização anaeróbica de glicose e manitol, a fim de identificá-las segundo a $\mathrm{APHA}^{(8)}$, assim como para a realização dos antibiogramas e detecção da enzima beta-lactamase.

Para o teste de sensibilidade antimicrobiana in vitro realizou-se prévia seleção de antibióticos, com base em pesquisas realizadas junto às casas agropecuárias do município de Zé Doca - MA. Os quatro antibióticos de maior procura para o tratamento de mastite foram codificados da seguinte forma: BPC (associação antimicrobiana à base de penicilina, estreptomicina, isoniazida e prednisolona), MPP (associação antimicrobiana à base de penicilina e estreptomicina), TOR (oxitetracilina base) e o TCA (cloridrato de tetraciclina). Para o referido teste, utilizou-se o Método de Difusão de Disco, no qual os isolados identificados como $S$. aureus e a cepa padrão ATCC 25923 foram testados frente aos antibióticos selecionados. Para isso, inoculou-se as cepas em Caldo Infusão de Cérebro e Coração e incubou-se a $37^{\circ} \mathrm{C}$ por 24 horas. Posteriormente, retirou-se de cada cultura uma alíquota de $0,1 \mathrm{~mL}$ e estirou-se sobre a superfície do Agar Müeller-Hinton. Em seguida, impregnou-se discos de $6 \mathrm{~mm}$ de diâmetro com os antibióticos selecionados, que foram colocados no centro da placa com o auxílio de pinça estéril e incubadas a $37^{\circ} \mathrm{C}$, por 24 horas. Transcorrido este período, fez-se a leitura dos halos de inibição com o auxílio de régua milimetrada, segundo metodologia recomendada pelo Clinical and Laboratory Standards Institute ${ }^{(9)}$. 
Os padrões de sensibilidade dos antibióticos frente aos isolados de Staphylococcus spp. seguiram o Manual para o Antibiograma do Laborclin ${ }^{(10)}$. Em decorrência da ausência de padrão dos halos provenientes da associação antimicrobiana do BPC e MPP, utilizou-se como referência o valor do halo observado para a penicilina. Já para os antibióticos TOR e TCA, utilizou-se os valores de halos inibitórios esperados para a Tetraciclina ${ }^{(10)}$. A detecção da produção da enzima beta-lactamase foi realizada através do teste de borda e seguiu metodologia recomendada pelo Laborclin ${ }^{(10)}$.

\section{Resultados e Discussão}

Todas as amostras demonstraram contaminação por Staphylococcus spp. com contagens de 1,9 x $10^{3}$ a 5,24 × $10^{6} \mathrm{UFC} / \mathrm{mL}$. Resultados similares foram verificadas por Ângelo et al. ${ }^{(11)}$ que, ao pesquisarem Staphylococcus spp. no leite cru armazenado em tanques refrigeradores, observaram valores superiores a $10^{3} \mathrm{UFC} / \mathrm{mL}$, sendo que três dos sete tanques apresentaram contagens acima de $10^{5}$ UFC/mL. Já Brites et al. ${ }^{(12)}$, ao analisarem amostras de leite cru provenientes de 37 tanques de expansão comunitários e individuais no município de Pomba - MG, verificaram contagem de estafilococos variando de $<1,0 \times 10^{1} \mathrm{UFC} / \mathrm{mL}$ estimada a $1,6 \times 10^{4} \mathrm{UFC} / \mathrm{mL}$.

As elevadas contagens observadas neste estudo podem estar associadas a fatores como microbiota natural do animal, higiene ou limpeza inadequadas dos utensílios utilizados durante a ordenha, falta de higiene pessoal dos ordenhadores e comercialização do leite sem refrigeração. Tais aspectos foram apontados em outras pesquisas como a de Santana et al. ${ }^{(13)} \mathrm{em}$ estudo envolvendo quatro propriedades com produção leiteira na região de Londrina (PR), no qual verificaram que os principais pontos de contaminação do leite foram a água residual de latões, tanques de expansão e tetos higienizados inadequadamente. Situação semelhante foi reportada por Sandes et al. ${ }^{(14)}$ em propriedades no Recôncavo Baiano, onde $90 \%$ das 18 propriedades não mecanizadas apresentavam falhas na higiene e limpeza da ordenha.

A Instrução Normativa $n^{\circ} 62$ que aprova o Regulamento Técnico de Produção, Identidade e Qualidade do Leite tipo A cru refrigerado e pasteurizado não estabelece limites para a presença de Staphylococcus spp. no leite cru, visto que a comercialização deste produto para consumo só é permitida após tratamento térmico eficaz para a eliminação deste microrganismo ${ }^{(15)}$. No entanto, sua presença em leite merece atenção por dar indícios sobre as condições do manejo realizado durante a ordenha e estado sanitário do animal.

$\mathrm{Na}$ identificação bioquímica, nove dos 13 isolados de Staphylococcus spp. obtidos do leite foram confirmados para $S$. aureus. Noel et al. ${ }^{(16)}$ realizaram estudo em fazendas da região Sul-Fluminense e, dentre os 207 isolados de Staphylococcus spp., 23 foram identificados com S. aureus. Almeida et $a l .{ }^{(17)}$ analisaram 326 amostras de leite in natura obtidas diretamente de latões após a ordenha ou em tanques de expansão, provenientes de 59 estabelecimentos familiares produtores de leite distribuídos em três municípios do Norte de Minas, e verificaram que em relação aos microrganismos mastitogênicos o Staphylococcus spp. foi isolado em 9,05\% (36) do total de amostras. As espécies identificadas no referido estudo foram $S$. aureus (52,8\%), S. intermedius (5,6\%), S. haemolyticus $(19,4 \%)$ e $S$. saprophyticus $(22,2 \%)$.

Quanto aos testes com os antibióticos comerciais BPC e MPP frente às cepas de $S$. aureus isoladas, verificou-se que 77,7\%, dentre elas a cepa padrão de $S$. aureus ATCC 25923, foram resistentes tanto 
para o antibiótico veterinário BPC quanto para o MPP e que 22,3\% foram sensíveis para ambos. O BPC é um antibacteriano injetável, com amplo espectro de ação, indicado nos processos infecciosos de mastites causadas por Staphylococcus spp., Streptococcus spp., e Corynebacterium pyogenes, porém o mesmo não apresentou eficácia na eliminação do $S$. aureus padrão ATCC 25923 e das cepas de $S$. aureus isoladas do leite cru, indicando uma resistência das cepas testadas frente ao antibiótico, o mesmo foi verificado para o medicamento MPP. O resultado da produção de beta-lactamases pelas estirpes de $S$. aureus isoladas do leite cru e cepa padrão para os antibióticos BPC e MPP demonstrou um percentual de 55,55\% das cepas positivas para ambos os antibióticos.

Tem-se observado uma crescente resistência bacteriana aos antimicrobianos convencionais, o que alerta para a necessidade da adoção de protocolos terapêuticos, preferencialmente respaldados em testes de susceptibilidade antimicrobiana in vitro ${ }^{(18)}$. Costa et al. ${ }^{(19)}$ relatam uma maior resistência de Staphylococcus isolados de casos de mastite clínica e subclínica, aos antimicrobianos do grupo dos betalactâmicos-penicilina, devido à produção de betalactamases com capacidade de cindir o anel betalactâmico da estrutura do antimicrobiano, constituindo-se no principal mecanismo de resistência. Pereira et al. ${ }^{(20)}$, avaliando o perfil de resistência a antimicrobianos de $S$. aureus isolados de leite de vacas com mastite e de leite cru proveniente de vacas sadias, detectaram que $70 \%$ dos isolados eram resistentes ao antibiótico penicilina, concordando com o presente trabalho. Nader Filho et al. ${ }^{(21)}$ pesquisaram a sensibilidade antimicrobiana dos $S$. aureus isolados de vacas com mastite em 10 propriedades rurais do Estado de São Paulo e observaram que 94,4\% das cepas foram sensíveis à estreptomicina, enquanto apenas $2,8 \%$ apresentaram sensibilidade para penicilina. Peles et al. ${ }^{(22)}$ analisaram o leite de vacas com mastite na Hungria e encontraram alta resistência aos antibióticos beta-lactâmicos, em especial à penicilina, o antibiótico de maior uso em casos de infecção da glândula mamária, ressaltando a importância do caráter multirresistente dos antibióticos desse grupo.

Em 1944, quando a penicilina foi lançada, em torno de $94 \%$ dos S. aureus isolados de humanos eram sensíveis, entretanto, em 1950, metade das cepas eram resistentes, e na década de 1960 começaram a aparecer surtos de cepas multiresistentes em hospitais ${ }^{(23)}$. Apesar disso, o seu emprego ainda é bastante acentuado no tratamento de infecções tais como a mastite, o que foi também observado na cidade de Zé Doca, onde 50\% dos antibióticos veterinários comercializados para tratamento dessa infecção têm como base a penicilina. Tal fato é preocupante, pois segundo Zafalon et al. ${ }^{(24)}$, o aumento da resistência bacteriana em amostras isoladas de processos infecciosos em humanos parece não se dever somente ao seu mau e intensivo uso, mas também pela transmissão via alimentos de origem animal, ou pelo contato direto com animais de produção.

Quanto aos antibióticos comerciais TCA e TOR, verificou-se sensibilidade em 44,44\% dos isolados frente ao TCA, enquanto que 33,33\% foram resistentes e $22,22 \%$ revelaram sensibilidade intermediária, demonstrando que a droga pode ser utilizada contra o agente isolado, no entanto em doses elevadas. No que se refere aos resultados encontrados para o antibiótico comercial TOR, $66,66 \%$ das cepas pesquisadas demonstraram sensibilidade, enquanto $33,33 \%$ exibiram sensibilidade intermediária.

As tetraciclinas são antibacterianos de amplo espectro, geralmente bacteriostáticos, que se difundem no interior das células do hospedeiro e ligam-se na subunidade $30 \mathrm{~S}$ do ribossomo, resultando em inativação da síntese protéica. A resistência a esse antibacteriano ocorre através da aquisição do elemento móvel contendo o gene tet, que codifica uma proteína efluxo, provocando a saída do antibiótico da célula ${ }^{(25-26)}$.

Vários estudos envolvendo a resistência aos antimicrobianos vêm sendo desenvolvidos nos últimos 
anos. Zafalon et al. ${ }^{(24)}$ investigaram os perfis de resistência aos antimicrobianos em 55 isolados de $S$. aureus de leite vacas em lactação e verificaram 91,8\% de sensibilidade e 1,4\% de resistência a tetraciclina, enquanto que $1,4 \%$ das cepas apresentou perfil intermediário. Da Silva et al. ${ }^{(27)}$ avaliaram o perfil de sensibilidade de 83 amostras de $S$. aureus em rebanhos leiteiros do município de Garanhuns - PE e encontraram baixas taxas de sensibilidade para penicilina G $(5 \%)$ e ampicilina (12\%), no entanto, as amostras foram sensíveis à tetraciclina (93\%) e cefalotina (100\%. Ribeiro et al. ${ }^{(28)}$ enumeraram os microrganismos causadores da mastite bovina em Rio Pomba - MG, e também encontraram maior sensibilidade para os isolados de $S$. aureus, quando testados frente ao antibiótico tetraciclina (66,66\%). Também Kaiser et al. ${ }^{(29)}$, verificando a sensibilidade de $S$. aureus isolados de casos de mastites bovinas na Região Noroeste do Estado do Rio Grande do Sul, observaram maior sensibilidade in vitro à tetraciclina (79\%) e cefalotina (78\%), e menor sensibilidade aos antibióticos ampicilina (56\%), penicilina (45\%) e eritromicina (29\%). Nota-se com esses resultados, que a tetraciclina vem sendo eficiente na eliminação ou redução do $S$. aureus, quando comparada aos demais antibióticos. No entanto, é importante ressaltar que ainda não existem dados na literatura sobre a resistência de $S$. aureus aos medicamentos antimicrobianos disponíveis no comércio varejista para uso animal testados na presente pesquisa, uma vez que todos os trabalhos supracitados utilizaram antibióticos puros.

Estima-se que mais de $50 \%$ das doenças infecciosas emergentes em humanos transmitidos por alimentos e água são causadas por bactérias provenientes de animais e do meio ambiente, refletindo em um grande número de cepas de microrganismos multirresistentes a drogas ${ }^{(30)}$.

Tal fato requer atenção, uma vez que as bactérias vêm adquirindo cada vez mais resistência às drogas introduzidas na medicina humana e veterinária de modo usual, o que exige medidas urgentes no combate ao surgimento de novas cepas bacterianas multirresistentes, inclusive aos medicamentos antimicrobianos recentemente comercializados, levando à consequências importantes, com efeitos diretos na problemática das infecções hospitalares ${ }^{(6)}$. Além disso, torna-se necessário maiores investimentos das indústrias farmacêuticas em pesquisas sobre o desenvolvimento de drogas utilizando princípios ativos naturais, em particular metabólitos de plantas medicinais, recentemente, demonstrado na literatura uma boa atividade frente a cepas de Staphylococcus isolados de leite de vacas com mastitite $^{(31)}$.

\section{Conclusões}

O leite cru produzido na cidade de Zé Doca apresenta elevadas contagens de Staphylococcus spp. no leite. Os isolados de $S$. aureus foram resistentes à maioria dos antimicrobianos testados, sendo o TOR (oxitetracilina base) o que apresentou maior eficiência na eliminação/redução dos mesmos. Diante disso, torna-se necessária a criação de medidas para combater o surgimento de novas cepas bacterianas e atuação das autoridades públicas, fiscalizando a comercialização desses medicamentos veterinários, visto que o uso indevido pode ter impactos sobre a saúde humana.

\section{Referências}

1. González FHD. Composição bioquímica do leite e hormônios da lactação. In: González FHD, Dürr JN, Fontaneli RS. Uso do leite para monitorar a nutrição e o metabolismo de vacas leiteiras. Porto Alegre: UFRGS; 
2001. p.5-22.

2. Ordóñez Pereda JA, Rodriguez MIC, Álvarez LF, Sanz ML, Minguillón GDGF, Perales LH, et al. Tecnologia de alimentos - Alimentos de origem animal. Porto Alegre: Artmed, 2005.

3. Lucheis SB. Vigilância para Staphylococcus aureus produtores de toxinas em leite. Pesq Tec. 2012; 9(1).

4. Da Costa GM, Barros RA, Custódio DAC, Pereira UP, Figueiredo DJ, Silva N. Resistência a antimicrobianos em Staphylococcus aureus isolados de mastite em bovinos leiteiros de Minas Gerais, Brasil. Arq Inst Biol. 2013; 80(3): 297-302.

5. Tibbetts RJ, Lin TL, Wu CC. Phenotypic evidence for inducible multiple antimicrobial resistance in Salmonella choleraesuis. FEMS Microbiol Lett. 2003; 218(2): 333-338. 2003.

6. Brasil. Agência Nacional de Vigilância Sanitária. Investigação e controle de bactérias multirresistentes. 2007.

7. Martins JFL, Martins ADO, Milagres RCRM, Andrade NJ. Resistência a antibióticos de Staphylococcus aureus isolados de dietas enterais em um hospital público de Minas Gerais. Semina Ci Biol Saúde. 2007; 28(1): 9-14.

8. APHA. American Public Health Association. Compendium of Methods for the Microbiological Examination of Foods. 4th ed. Washington, 2001.

9. CLSI. Clinical and Laboratory Standards Institute. Performance standards for antimicrobial disk susceptibility tests; approved standard—eleventh edition. Replaces M02-A10. 2012; 29(1).

10. LABORCLIN. Manual para Antibiograma: difusão em disco (Kirby\&Bauer), 2011. Disponível em: < http://www.interlabdist.com.br/dados/noticias/pdf_190.pdf>. Acesso em: 31 out. 2016.

11. Ângelo FF, Barbosa AAO, Araújo TF. Staphylococcus coagulase positivo isolado de leite cru de tanques comunitários. Rev Cien Med Vet. 2014; 22.

12. Brites ASS, Martins ML, Martins EMF, Talma SV, Barbosa JB, Ribeiro RAP. Enumeração, isolamento, caracterização e controle da multiplicação de Staphylococcus aureus isolado de leite cru granelizado. Persp online Biol Saúde. 2013; 9(3): 28-36.

13. Santana EHW, Beloti V, Muller EE, Ferreira MA, Moraes LB, Pereira MS, et al. Milk contamination in different points of the dairy process. ii) mesophilic, psychrotrophic and proteolytic. Semina Ci Agr. 2004; 25(4): 349-358.

14. Sandes AB, Barros LSS, Silva MH, Santos ESV. Contagem de micro-organismos indicadores em leite cru obtidos por ordenha não mecanizada e mecanizada de propriedades do recôncavo baiano. Rev Bras Hig San Anim. 2016; 10(2): 396-414.

15. Brasil. Ministério da Agricultura, Pecuária e Abastecimento. Instrução Normativa 62 de 29 de dezembro de 2011. Dispõe sobre regulamentos técnicos de produção, identidade, qualidade, coleta e transporte do leite. Diário Oficial da União, Brasília, Seção 1, 30 dez. 2011.

16. Noel CC, Motta FS, Francisco NLSG, Almeida NR, Soares LC. Perfil de suscetibilidade antimicrobiana e produção de "slime" de isolados de Staphylococcus spp. provenientes de casos de mastite bovina na região sul-fluminense. Rev de Saúde. 2016; 7(1): 22-26.

17. Almeida AC, Santos CA, Menezes IR, Teixeira LM, Costa JPR, Souza RM. Perfil sanitário de unidades agrícolas familiares produtoras de leite cru e adequação à legislação vigente. Ci Anim Bras. 2016; 17(3): 303315 .

18. Langoni H, Domingues PF, Baldini S. Mastite caprina: seus agentes e sensibilidade frente a 
antimicrobianos. Rev Bras Ci Vet. 2006; 13(1): 51-54.

19. Costa EO, Garino Jr F, Ribeiro AR, Watanabe ET, Melville PA, Benites NR et al. Resistência aos antimicrobianos de microrganismos do gênero Staphylococcus isolados de mastite bovina no decênio de 1992 a 2001. Rev Napgama. 2004; 7(2): 13-20.

20. Pereira V, Lopes C, Castro A, Silva J, Gibbs P, Teixeira P. Characterization for enterotoxin production, virulence factors, and antibiotic susceptibility of Staphylococcus aureus isolates from various foods in Portugal. Food Microbiol. 2009; 26(3): 278-282.

21. Nader Filho A, Ferreira LM, Do Amaral LA, Rossi Junior OD, Oliveira RP. Sensibilidade antimicrobiana dos Staphylococcus aureus isolados no leite de vacas com mastite. Arq Inst Biol. 2007; 74(1):1-4.

22. Peles F, Wagner M, Varga L, Hein I, Rieck P, Gutser K, et al. Characterization of Staphylococcus aureus strains isolated from bovine milk in Hungary. Int J Food Microbiol. 2007; 118(2): 186-193.

23. Livermore DM. Antibiotic resistance in staphylococci. Int J Antimicrob Agents. 2000; 16: 3-10.

24. Zafalon LF, Arcaro JRP, Nader Filho A, Ferreira LM, Castelani L, Benvenutto F. Investigação de perfis de resistência aos antimicrobianos em Staphylococcus aureus isolados na ordenha de vacas em lactação. Rev Inst Adolfo Lutz. 2008; 67(2): 118-125.

25. Chopra I, Roberts M. Tetracycline antibiotics: mode of action, applications, molecular biology, and epidemiology of bacterial resistance. Microbiol Mol Biol Ver. 2001; 65(2): 232-260.

26. Alterthum F. Mecanismos de Ação dos Antibacterianos e Mecanismos de Resistência. In: Trabulsi LR, Alterthum F. Microbiologia. $5^{\text {a }}$ ed. São Paulo: Editora Atheneu, 2008.

27. Da Silva ER, Pereira AMG, Moraes WS, Santoro KR, Silva TRM.Perfil de sensibilidade antimicrobiana in vitro de Staphylococcus aureus isolado de mastite subclínica bovina. Rev Bras Saúde Prod Anim. 2012; 13(3): 701-711.

28. Ribeiro WO, Oliveira RL, Martins ML, Martins JM, Arcanjo AHM, Almeida Neto OB. Enumeração de microrganismos causadores da mastite bovina e estudo da ação de antimicrobianos. Rev Inst Laticínios Cândido Tostes. 2014; 69(1): 45-52.

29. Kaiser TS, Possebon KF, Viero LM, Martins LV. Sensibilidade antimicrobiana de Staphylococcus aureus isolados em mastites bovinas na região noroeste do estado do Rio Grande do Sul. In: XXIII Seminário De Iniciação $\quad$ Científica. $\quad 2015 . \quad$ Disponível em: $<$ https://www.revistas.unijui.edu.br/index.php/salaoconhecimento/article/viewFile/5117/4297> Acesso em: 31 out. 2016.

30. Jones KE, Patel NG, Levy MA, Storeygard A, Balk D, Gittleman JL, Daszak P. Global trends in emerging infectious siseases. Nature. 2008; 451(7181): 990-993.

31. Faria MJM, Braga CASB, Paula JR, André MCDPB, Vaz BG, Carvalho TC, Romão W, Costa HB, Conceição EC. Antimicrobial Activity of Copaifera spp. Against Bactéria Isolated from Milk of Cows With Mastitis. Ciencia Animal Brasileira. 2017; 18. 